\title{
Fluctuating Loads on a Tidal Turbine Due to Velocity Shear and Turbulence: Comparison of CFD with Field Data
}

DOI:

10.1016/j.renene.2017.05.048

\section{Document Version}

Accepted author manuscript

Link to publication record in Manchester Research Explorer

\section{Citation for published version (APA):}

Ahmed, U., Apsley, D., Afgan, I., Stallard, T., \& Stansby, P. (2017). Fluctuating Loads on a Tidal Turbine Due to Velocity Shear and Turbulence: Comparison of CFD with Field Data. Renewable Energy, 112, 235-246.

https://doi.org/10.1016/j.renene.2017.05.048

\section{Published in:}

Renewable Energy

\section{Citing this paper}

Please note that where the full-text provided on Manchester Research Explorer is the Author Accepted Manuscript or Proof version this may differ from the final Published version. If citing, it is advised that you check and use the publisher's definitive version.

\section{General rights}

Copyright and moral rights for the publications made accessible in the Research Explorer are retained by the authors and/or other copyright owners and it is a condition of accessing publications that users recognise and abide by the legal requirements associated with these rights.

\section{Takedown policy}

If you believe that this document breaches copyright please refer to the University of Manchester's Takedown Procedures [http://man.ac.uk/04Y6Bo] or contact uml.scholarlycommunications@manchester.ac.uk providing relevant details, so we can investigate your claim.

\section{OPEN ACCESS}




\title{
Fluctuating Loads on a Tidal Turbine Due to Velocity Shear and Turbulence: Comparison of CFD with Field Data
}

\author{
Ahmed, U., Apsley ${ }^{1}$, D.D., Afgan, I., Stallard, T. and Stansby, P.K. \\ University of Manchester, Sackville Street, Manchester, M13 9PL, UK
}

\begin{abstract}
Fluctuating loads on tidal turbines are important for fatigue analysis and there is limited information or simulation available for full-scale conditions. Here, CFD simulations have been performed for a geometry-resolved full-scale tidal-stream turbine and compared with experimental data from a $1 \mathrm{MW}$ machine deployed at the EMEC test site. Initially, Reynoldsaveraged Navier-Stokes (RANS) and large-eddy simulations (LES) were performed using an inflow mean velocity profile representative of the site but low inflow turbulence. Mean blade pressures were similar for the two types of turbulence closure and yielded mean power coefficients comparable with measurements. Then, to simulate the effect of turbulence on loads, LES with synthetic turbulence prescribed at inlet was employed. For these simulations, inflow profiles of mean velocity, Reynolds stresses and length scales were determined from a precursor channel-flow simulation, with additional factoring of stresses and length scales to match hub-height conditions measured on site. Fluctuations in thrust, power and blade bending moment arise cyclically from onset mean velocity shear and the blocking effect of the support tower and over continuous spectral ranges from blade-generated turbulence, approach-flow turbulence and waves. LES simulations with realistic inflow turbulence satisfactorily reproduced the relative spectral distribution of blade bending moments in lowwave conditions.
\end{abstract}

Keywords: tidal-stream turbine; computational fluid dynamics; large-eddy simulation; synthetic-eddy modelling; load spectra.

\section{INTRODUCTION}

Tidal resources have long been considered a promising source of renewable energy, offering high energy density and predictable generating periods. Public opposition to the expense and unknown environmental consequences of large barrages have led to tidal-stream turbines predominantly axial-flow devices - which aim to extract kinetic energy from the tidal current rather than the potential energy built up by impounding water. In numerous sites around the world narrow straits lead to tidal currents in excess of $2.5 \mathrm{~m} \mathrm{~s}^{-1}$, where tidal-stream energy becomes commercially viable [1], [2]. A large number of demonstration devices have been tested at the EMEC site in the Orkney Isles and the FORCE site in Nova Scotia's Bay of Fundy, whilst commercial arrays are under construction in the Pentland Firth off Scotland (MeyGen) and the Raz Blanchard off Normandy (GE/GDF Suez and OpenHydro/EDF).

Unsurprisingly, given the cost of designing and testing radically new devices, tidal-stream technology has been heavily influenced by the more mature technology of windpower. Most devices are of the three-bladed, horizontal-axis type. (The ducted turbines of OpenHydro are a notable exception.) Typical commercial turbines have variable-pitch blades, a diameter of

\footnotetext{
${ }^{1}$ Corresponding author (d.apsley@manchester.ac.uk)
} 

encountered by windpower - the requirement for a much more substantial nacelle and support tower, short deployment window and difficulty of access, bio-fouling, marine debris, cavitation, and additional fluctuating loads due to waves.

Small-scale laboratory studies have been conducted in flumes and towing tanks, including the effects of cavitation [3], waves [4], turbulence [5] and in-array operation [6]. Turbine wakes may be simulated by scale-model rotors or by porous disks causing similar momentum deficit [7]. However, laboratory studies are only able to cover a limited range of operating conditions and are subject to scale effects. Theoretical modelling includes blade-elementmomentum theory (BEMT), as performed by Bahaj et al. [8] and incorporated in DNV GL's TidalBladed software, and computational fluid dynamics (CFD). Because supercomputing resources are now becoming more widely available, CFD is increasingly being used as a design tool. It offers geometric flexibility, absence of scale effects and the ability to incorporate many of the specific design challenges for tidal-stream turbines (TSTs). It has the ability to simulate realistic onset velocity profiles and turbulence which affect fluctuating loads and fatigue. Nevertheless, CFD depends on many embedded models - notably in its treatment of turbulence - and its range of validity needs to be established by comparison with real field data if it is to be accepted as a reliable design tool. For complex 3-dimensional geometries it is also computationally-demanding to achieve satisfactory numerical accuracy.

Just as laboratory experiments may use geometrically-accurate models or porous disks of comparable cross-section and resistance, CFD simulations of tidal-stream or wind turbines may be divided into those which attempt to simulate the actual geometry of the turbine rotor $[9,10,11]$ and those which replace the "real" geometry by the set of reaction forces that it produces - so-called "actuator models" $[12,13]$. The latter are particularly advantageous for turbines in arrays $[14,15,16]$ or tidal-stream turbines in waves [17], where the computational resources required to fit boundary-layer-type grids around complex, moving shapes would be prohibitive. However, such models are unable to fully describe near-wake flow structure or resolve the fluctuations associated with blade-generated turbulence.

Fluctuations in individual-blade and whole-rotor loading have a number of distinct spectral components. Discrete multiples of rotation frequency are associated with tower passing and onset mean-velocity shear. Continuous spectral ranges arise from onset flow turbulence (low to mid frequency) and blade-generated turbulence (high frequency).

In this paper we describe the CFD simulation of an individual $1 \mathrm{MW}$ turbine which has recently been deployed and tested at the EMEC test site in the Orkneys as part of the ETIfunded ReDAPT (Reliable Data Acquisition Platform for Tidal) project and for which fluctuating load and velocity data, as well as onset velocity profiles, are available [18, 19, 20]. The simulations in this paper include a geometrically-accurate representation of the turbine rotor and nacelle, and employ realistic inflow profiles of mean and turbulent velocity fields based on measurements from the deployment site. Time-dependent Reynolds-averaged Navier-Stokes (RANS) simulations provide estimates of mean flow and loading, including velocity-shear (i.e. onset mean-velocity profile) and tower-passing effects, whilst more computationally-intensive large-eddy simulation (LES) simulations allow us to quantify the fluctuations in whole-rotor and individual-blade loads and compare with the statistics and spectra recorded during operation of the $1 \mathrm{MW}$ turbine. 
The structure of the remainder of this paper is as follows. Section 2 describes the geometrical configuration and numerical methods, including the CFD modelling of moving elements and the generation of realistic inflow turbulence using a synthetic eddy method (SEM). Section 3 compares predictions of mean and fluctuating blade loads, including spectra, with experiment, and shows CFD predictions of the turbine effects on the flow field, which has implications for downstream devices. Section 4 draws conclusions about the ability of the simulations to capture full-scale effects and outlines the direction of future work.

\section{TEST CASE AND CFD METHODOLOGY}

\subsection{Turbine Details and Load Parameters}

The turbine is the $1 \mathrm{MW}$ DEEP-Gen IV turbine of Alstom Ocean Energy (since acquired by GE) which was deployed for testing at the Fall of Warness EMEC site in the Orkneys in the autumn of 2013. The full-scale rotor is 3-bladed with swept diameter $D=18.3 \mathrm{~m}$, whilst the nacelle is $22 \mathrm{~m}$ long. The conditions simulated here were compared against data windows representing near-design conditions: onset velocities of $1.8-2.7 \mathrm{~m} \mathrm{~s}^{-1}$, tip-speed ratios of 5 6 and a fixed blade pitch (although the operational turbine has variable-pitch capabilities). Measurements of onset velocity conditions have been reported by [18], turbine load data by [19] and BEMT-type simulations of fluctuating load by [20].

To compare data collected at different current speeds, results are presented in nondimensional form. The main performance-related parameters are defined below.

$$
\begin{array}{ll}
\text { Tip-speed ratio: } & \mathrm{TSR} \equiv \frac{\Omega R}{U_{0}} \\
\text { Thrust coefficient: } & C_{T}=\frac{\text { force }_{x}}{\frac{1}{2} \rho U_{0}^{2} A} \\
\text { Power coefficient: } & C_{P}=\frac{\text { torque } \times \text { angular velocity }}{\frac{1}{2} \rho U_{0}^{3} A}
\end{array}
$$$$
\text { Blade bending moment: } \quad C_{B M}=\frac{\text { bending moment }}{\frac{1}{2} \rho U_{0}^{2} A R}
$$

Here, $R$ is the tip radius, $A$ is the rotor swept area and $\Omega$ is the angular velocity (assumed constant throughout this paper, although, in reality, rotation rate will change depending on control mechanisms, onset flow variation and the inertia of the rotor). $U_{0}$ is a suitable approach-flow reference velocity. In a shear flow the last is ambiguous and there are a number of possible candidates, including bulk (depth-averaged) mean velocity $\left(U_{b}\right)$, mean velocity at hub height $\left(U_{h u b}\right)$, mean velocity averaged over the turbine swept area $\left(U_{A}\right)$ and power-weighted (based on the average of $U^{3}$ over the turbine swept area). In order to compare directly with the available experimental data, in this paper $U_{0}$ is taken as the hubheight velocity, as this was measured in real time by a turbine-mounted instrument. In the CFD calculations, hub-height velocity was extracted one diameter upstream of the turbine, rather than the inflow plane: allowing for flow development between inflow and rotor but upstream of the region of influence of the turbine and its nacelle.

For blade bending moments, two axes may be considered: flapwise (moment of forces about the chord line) and edgewise (moment of forces about an axis in the plane of the cross-section 
and perpendicular to the chord at the "pitch axis"; here, 35\% chord from the leading edge). Figure 1 defines the axes for these moments.

Figure 1. Definition of axes for blade bending moments.

Computationally, bending moments are computed by projecting the net moment of force about the reference point $\mathbf{r}_{r e f}$ onto a unit vector in the direction of the relevant axis, $\mathbf{e}_{\text {axis }}$ :

$$
M_{\text {axis }}=\mathbf{e}_{\text {axis }} \bullet \sum\left(\mathbf{r}-\mathbf{r}_{\text {ref }}\right) \wedge \mathbf{F}
$$

where $\mathbf{F}$ is the net surface force (pressure plus shear stress) on a blade-surface cell face and the summation is over surface cell faces at greater radius than the reference point.

In this paper comparisons are made only for flapwise bending moments at $1.16 \mathrm{~m}$ from blade root (2.45 $\mathrm{m}$ from rotor centre line, or $r / R=0.272)$.

\subsection{CFD Code and Turbulence Modelling}

Calculations were performed with version 2.06 of EDF's open-source CFD solver Code_Saturne (http://code-saturne.org/). This code is well-suited to massively-parallel computations (here, typically 4096 processor cores on EDF's Blue Gene Q supercomputer). Its open-source nature also allowed us to implement our own sliding-mesh interface [21] and post-processing routines. Computation times for a resolved rotor were substantial, a single turbine rotation taking about a day for RANS and a week for LES.

Code_Saturne is an unstructured-mesh, finite-volume solver. On a moving mesh (Section 2.3 ), integral conservation equations are solved for each transported variable $\phi$ of the form

$$
\frac{\mathrm{d}}{\mathrm{d} t} \int_{V} \rho \phi \mathrm{d} V+\oint_{\partial V} \rho\left(\mathbf{u}-\mathbf{u}_{g r i d}\right) \phi \bullet \mathrm{d} \mathbf{A}=\oint_{\partial V} \mathbf{f} \bullet \mathrm{d} \mathbf{A}+\int_{V} S \mathrm{~d} V
$$

where $V$ is a cell volume with bounding surface $\partial V$, $\mathbf{f}$ is non-advective flux density and $s$ is source density. When $\phi$ is a velocity component, $\mathbf{f}$ comprises pressure, viscous and modelled turbulent stress terms. $\mathbf{u}$ is the resolved velocity field. In the arbitrary Lagrangian-Eulerian (ALE) method, $\mathbf{u}_{\text {grid }}$ represents the prescribed motion of the mesh, with $\Delta t \mathbf{u}_{\text {grid }} \bullet \mathrm{d} \mathbf{A}$ being the volume swept out by face area $\mathrm{d} \mathbf{A}$ in one time step $\Delta t$. A pressure-correction method is used to enforce mass conservation, with second-order discretisation in space and time for advective fluxes and time derivative respectively. 
179 Two levels of turbulence modelling were undertaken: RANS calculations using the SST $k$ - $\omega$ 180 model [22] and LES calculations with the dynamic subgrid-scale model of Germano et al. 181 [23], as modified by the popular least-squares formulation of Lilly [24]. In the last, the subgrid-scale eddy viscosity is given by:

$$
\frac{\mu_{S G S}}{\rho}=C \Delta^{2}\|\mathbf{S}\|
$$

where the resolved rate-of-strain tensor and its norm are

$$
S_{i j}=\frac{1}{2}\left(\frac{\partial u_{i}}{\partial x_{j}}+\frac{\partial u_{i}}{\partial x_{j}}\right), \quad\|\mathbf{S}\|=\sqrt{2 S_{i j} S_{i j}}
$$

and $\Delta$ is the filter width (i.e. resolvable length scale), related to the grid size. In Code_Saturne it is taken as

$$
\Delta=2(\text { cell volume })^{1 / 3}
$$

189 In the classic LES model of Smagorinksy [25], $C$ is a constant, with default value $0.065^{2}$ in

190 Code_Saturne. In the dynamic model $C$ varies in time and space. In Lilly's formulation, 191 minimising the squared difference between unresolved stress and strain on grid scale $\Delta$ and a

where larger scale $\hat{\Delta}$ gives

$$
C=\frac{L_{i j} M_{i j}}{M_{i j} M_{i j}}
$$

\subsection{Computational Mesh}

Starting from turbine and nacelle geometry supplied as CAD files, but simplifying the tripod support tower to a simple monopile, a mesh was produced using ICEM CFD. The computational domain and position of the turbine are shown in Figure 2. The domain was divided into an inner cylindrical region of cells (diameter 1.09D), containing the turbine rotor, which rotated inside a stationary outer domain that included the support tower. Coupling between domains was achieved by a simple sliding-interface method [21]. Total cell counts were 8.4 million and 17.6 million for RANS and LES calculations respectively, with slightly over half the cells in the rotating region. The RANS mesh had 78 and 50 cells radially and chord-wise respectively along the blade. Similar figures for the LES mesh were 109 and 92. As a mesh-independence test, a higher-resolution LES mesh produced the same mean power coefficient, but at considerably greater computational expense. The mesh is sufficient for the fluctuating turbine load parameters with which we were concerned, but a 
similar level of resolution for the whole of the downstream wake region would be computationally impractical. Figure 3 shows details of the mesh near the turbine.

225

226

227

228

229

230

231

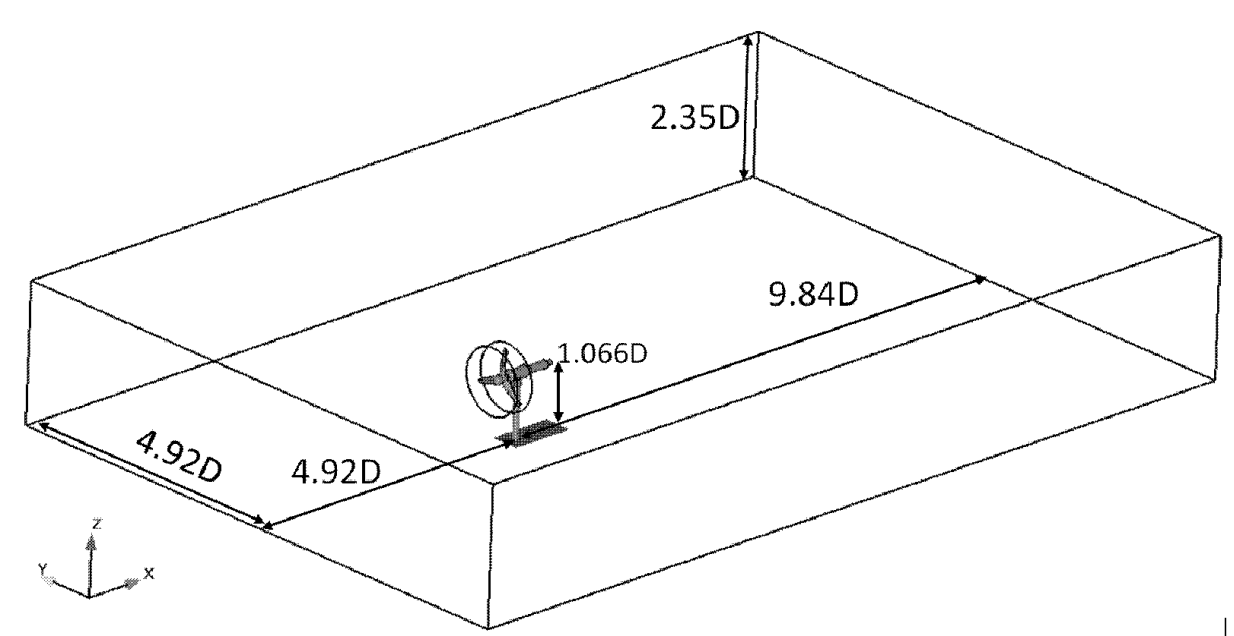

Figure 2. Computational domain and turbine position.

(a)

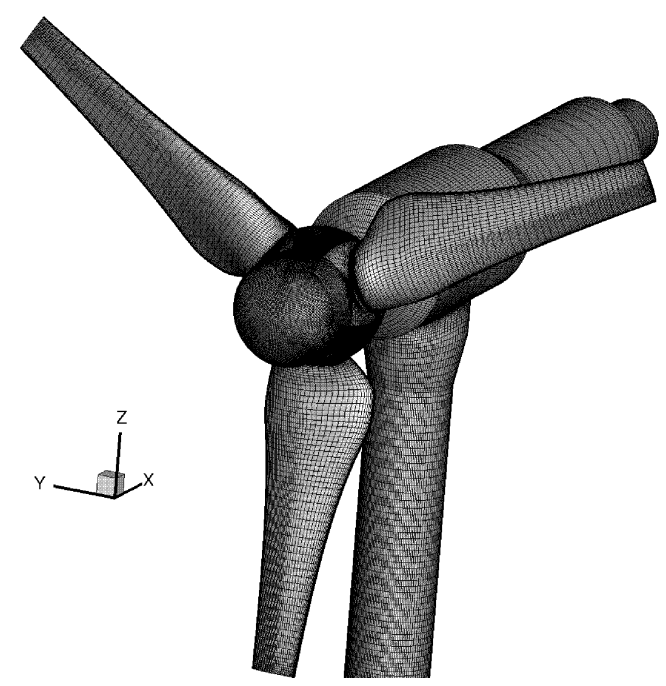

(b)

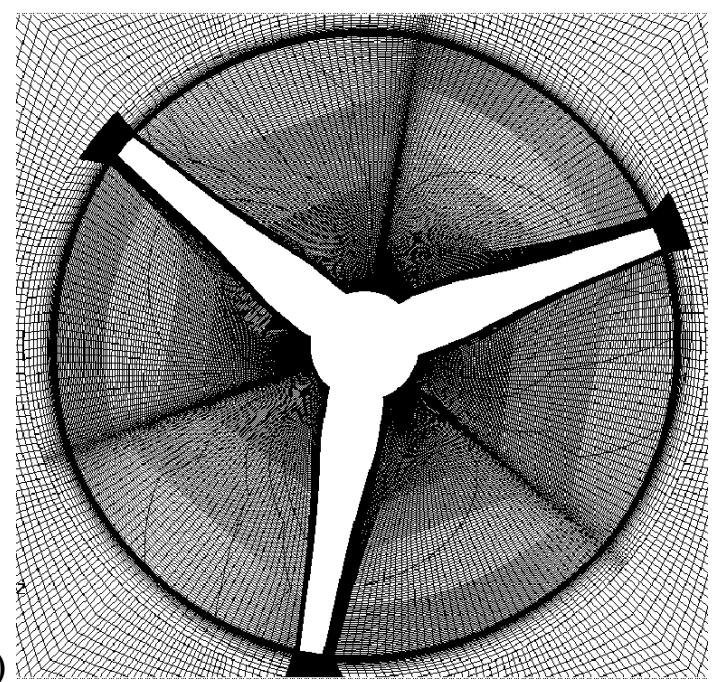

Figure 3. Computational mesh: (a) surface detail; (b) cross-stream mesh in the rotating region.

\subsection{Inflow Conditions}

\subsubsection{Mean-Velocity and Turbulent Stress Profiles}

Measurements to characterise the flow at the Fall of Warness site consisted of two seabedmounted acoustic-Doppler current profilers (ADCPs) giving mean-velocity profiles over the water column and a number of single-beam Doppler (SBD) devices mounted on the turbine to determine turbulence intensity and length scale. Depth profiling from the ADCPs also 
enabled the filtering out of periods of high wave activity, focusing instead on the impact of turbulence in the onset flow.

To simulate computationally both mean and fluctuating loads it is desirable to prescribe the Fall of Warness site mean that any measurement-based velocity profile will be far from fully-developed, and in any computational simulation with significant turbulence there will inevitably be flow development between inlet plane and turbine rotor. Measurements also cannot provide all the required turbulence statistics (particularly length scales) necessary to synthesise turbulence at inflow for the LES calculations.

To examine the effects of onset velocity shear and turbulence we conducted simulations for three inflow conditions. The different modelling strategies and inflow conditions (which are summarised in Table 1) were as follows.

- Mean velocity profile based on a representative flood tide at the site [18], with nearzero turbulence to ensure that this profile was sustained as far as the rotor. Simulations were performed with RANS (case A in Table 1) and LES (case B).

- $\quad$ Turbulence and mean-velocity profiles based on a separate fully-developed LES channel-flow simulation (at a much lower Reynolds number); LES only (case C).

- Turbulence and mean-velocity profiles from a fully-developed channel-flow simulation as above, but with length scales multiplied by 0.5 and Reynolds stresses multiplied by 1.8 to match recorded data at hub-height; LES only (case D).

Figure $4 \mathrm{a}$ shows the two different mean-velocity profiles, whilst Figure $4 \mathrm{~b}$ compares channelflow profiles of mean and streamwise turbulent velocity (after factoring to match hub-height average stress) with those recorded on site. There is good agreement in normalised profiles at rotor height (19 m, or $0.45 h$, where $h$ is depth), but some difference nearer the bed because of site-specific conditions and the fact that the detailed channel-flow simulations were undertaken at a significantly lower Reynolds number (friction Reynolds number $\operatorname{Re}_{\tau}=9300$, rather than 630000 at full scale). Unfactored Reynolds stresses and length scales from the channel-flow simulations are shown in Figure 5. Definitions of the length scales are given in the next section.

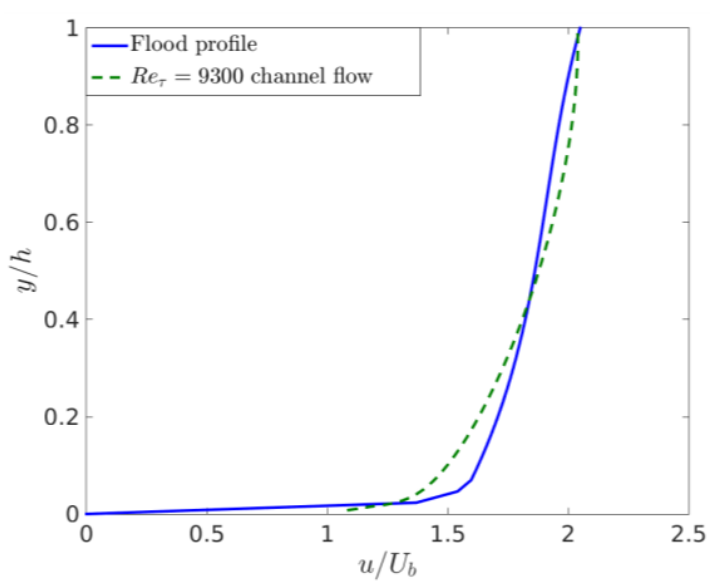

(a)

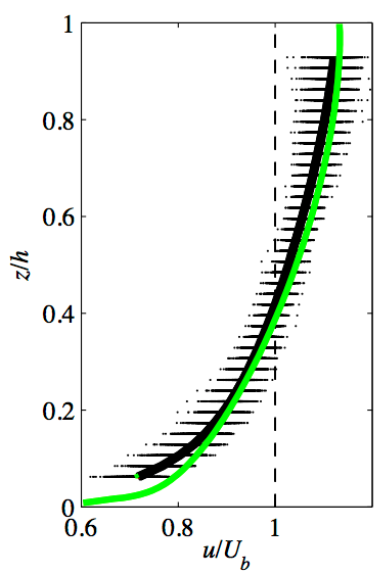

(b)

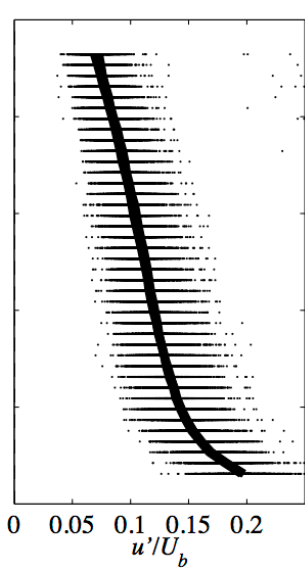

Figure 4. Velocity profiles at inlet: (a) representative flood-tide profile and channel-flow simulation; (b) comparison of channel-flow-derived streamwise mean and fluctuating velocities with the range of values observed at the deployment site. 


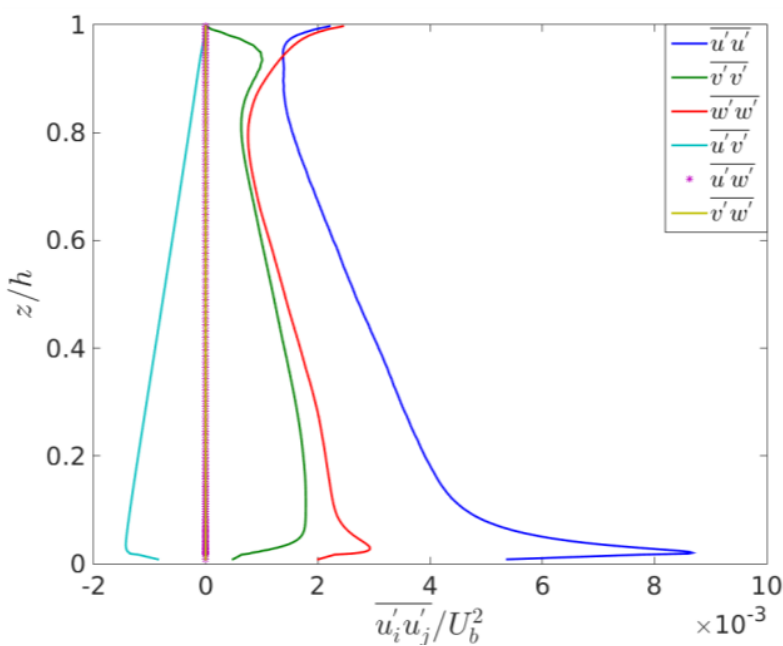

(a)

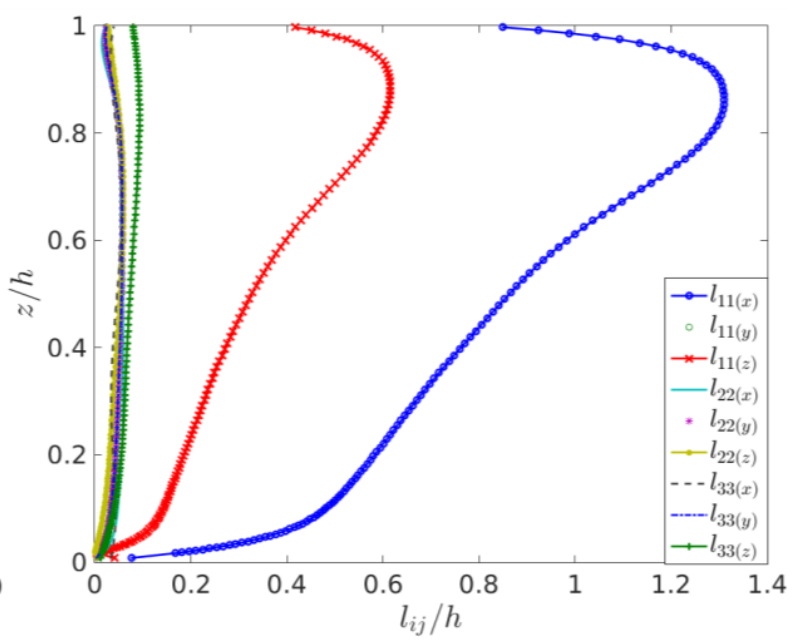

(b)

Figure 5. Turbulence profiles from the channel-flow simulation: (a) Reynolds stresses; (b) length scales.

\begin{tabular}{|l|l|l|l|l|l|}
\hline Case & $\begin{array}{l}\text { Turbulence } \\
\text { closure }\end{array}$ & $\begin{array}{l}\text { Inlet mean } \\
\text { velocity profile }\end{array}$ & Inlet turbulence & $\begin{array}{l}U_{\text {hub }} \\
\left(\mathrm{m} \mathrm{s}^{-1}\right)\end{array}$ & TSR \\
\hline A & $\begin{array}{l}\text { RANS } \\
\text { SST } k-\omega)\end{array}$ & Flood tide & Zero (nominal) & 1.84 & 5.86 \\
\hline B & LES & Flood tide & Zero & 1.85 & 5.86 \\
\hline C & LES & Channel flow & Channel flow & 1.73 & 5.07 \\
\hline D & LES & Channel flow & $\begin{array}{l}\text { Channel flow; factored length } \\
\text { scales and stresses }\end{array}$ & 2.48 & 5.07 \\
\hline
\end{tabular}

Table 1. Summary of flow cases considered.

\subsubsection{Synthetic Eddy Model for LES Calculations}

Synthetic eddy modelling (SEM) is used to provide an LES calculation with a fluctuating inlet velocity field for any prescribed statistical distribution of Reynolds stresses and turbulent length scales. The SEM used here is based on the work of [26].

Fluctuating velocities are generated from eddies advected through a virtual box (volume $V_{B}$ ) containing the nominal inlet plane (Figure 6) at a constant speed equal to the bulk velocity. When one eddy leaves the box another eddy is generated at a random location on the box inlet plane. The velocity fluctuation in direction $\alpha$ is given by

$$
u_{\alpha}^{\prime}(\mathbf{x})=\frac{1}{\sqrt{N}} \sum_{e d d y=1}^{N} \sum_{\beta=1}^{3} a_{\alpha \beta} \varepsilon_{\beta}^{e d d y} F\left(\mathbf{x}-\mathbf{x}_{e d d y}, \alpha\right)
$$

where $N$ is the number of eddies in the box, $\mathbf{x}_{e d d y}$ is the eddy centre, $a_{\alpha \beta}$ are the Lund coefficients (Cholesky decomposition $\mathbf{a}^{T} \mathbf{a}$ of symmetric tensor $\overline{u_{i} u_{j}}$ ), $\varepsilon_{\beta}^{\text {eddy }}$ are a set of random numbers with mean 0 and variance 1 , and the shape function is 


$$
F(\mathbf{x}, \alpha)=\sqrt{\frac{V_{B}}{L_{\alpha}^{3}}} f\left(\frac{x}{L_{\alpha x}}\right) f\left(\frac{y}{L_{\alpha y}}\right) f\left(\frac{z}{L_{\alpha z}}\right)
$$

312 where

$$
L_{\alpha}=\frac{1}{3}\left(L_{\alpha x}+L_{\alpha y}+L_{\alpha z}\right), \quad f(\xi)=\max \left(\sqrt{\frac{3}{2}}(1-|\xi|), 0\right)
$$

314 Here, $L_{\alpha x}, L_{\alpha y}$ and $L_{\alpha z}$, are the integral length scales of the $\alpha$ velocity component, determined

315 from two-point correlations in fully-developed flow by

$$
L_{\alpha \beta}=\frac{1}{\overline{u_{\alpha}^{2}}} \int_{0}^{\infty} \overline{u_{\alpha}(\mathbf{x}) u_{\alpha}\left(\mathbf{x}+r \mathbf{e}_{\beta}\right)} \mathrm{d} r
$$

9 integral length scales are required -3 directions for each of 3 velocity components - and each is a function of height $z$.

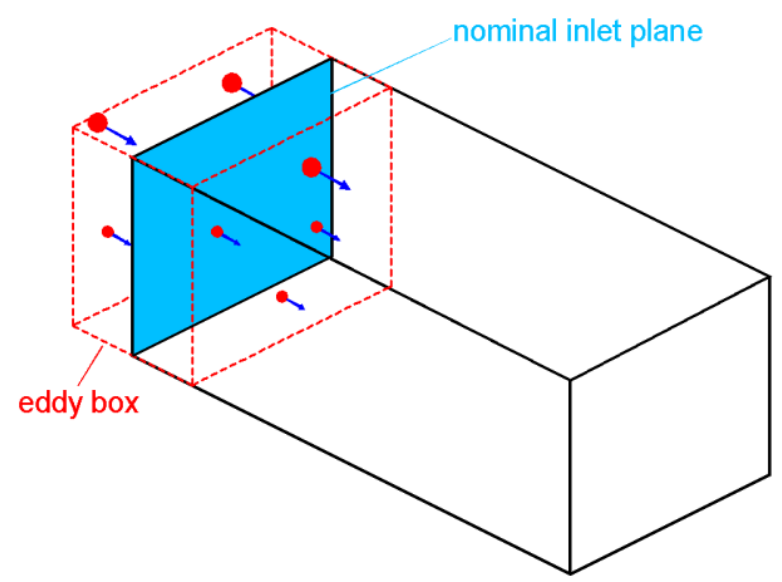

Figure 6. Eddy box for synthetic inflow turbulence.

The main inputs to the SEM are thus the vertical profiles of length scales $L_{\alpha \beta}$ and stresses $\overline{u_{\alpha} u_{\beta}}$. For this work they have been derived from a fully-developed channel-flow LES, scaled to the desired bulk velocity $U_{b}$ and depth $h$ (Figure 5). In case D above (see Table 1) both length scales and stresses have been factored to match experimental conditions at hub height.

\section{RESULTS}

\subsection{Velocity field}

Obtaining field measurements of the turbine-affected flow is not trivial and this is one area where CFD can potentially yield much more detailed information than either field or laboratory measurements. Here, it is instructive to compare the qualitative behaviour of the flow field for the different inflow conditions, particularly the impact of realistic onset turbulence on wake development.

Figure 7 shows the instantaneous velocity field from RANS and LES simulations, in the latter case comparing the effects of zero turbulence inflow to that synthesised by SEM. Mean inflow velocities are largely maintained up to the point where the effect of the rotor is felt, about $1 / 2$ to 1 diameters upstream. Turbulent eddies synthesised at inflow have a streamwise length comparable to water depth and are advected as far as the turbine rotor, but broken 
down rapidly in the wake. The wake is relatively narrow and sharply-defined by the swept disk of the rotor, with velocities dropping to about half their approach-flow value immediately downstream. Influenced by the confines of the channel and the blade-tip vortices, the near wake spreads comparatively little and the velocity field recovers only slowly, with slightly greater spreading rate in the higher turbulence cases. There are significant wakes associated with the nacelle and support tower.

(a)

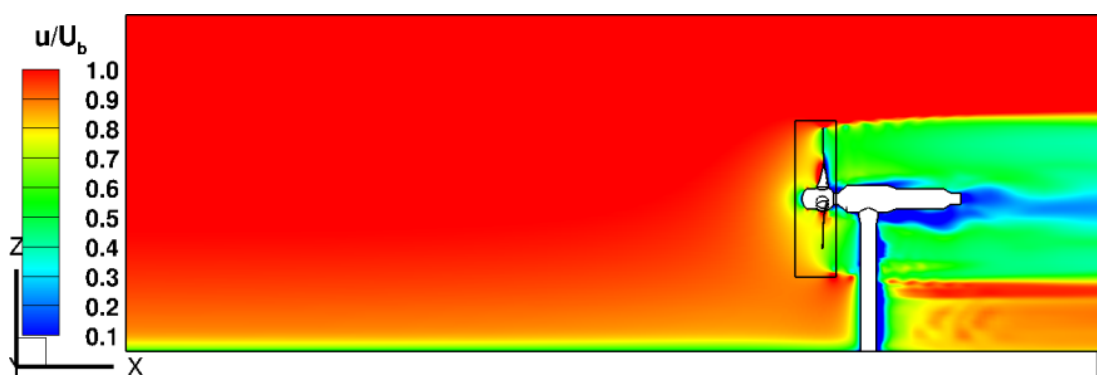

(b)

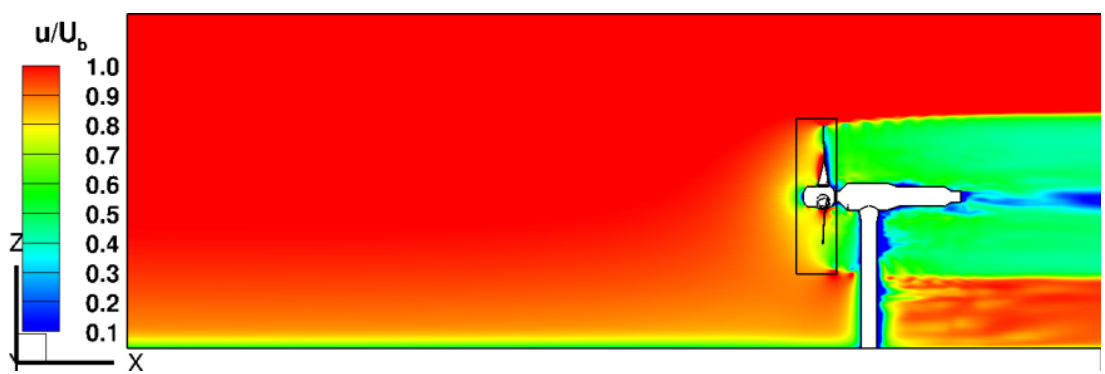

356

(c)

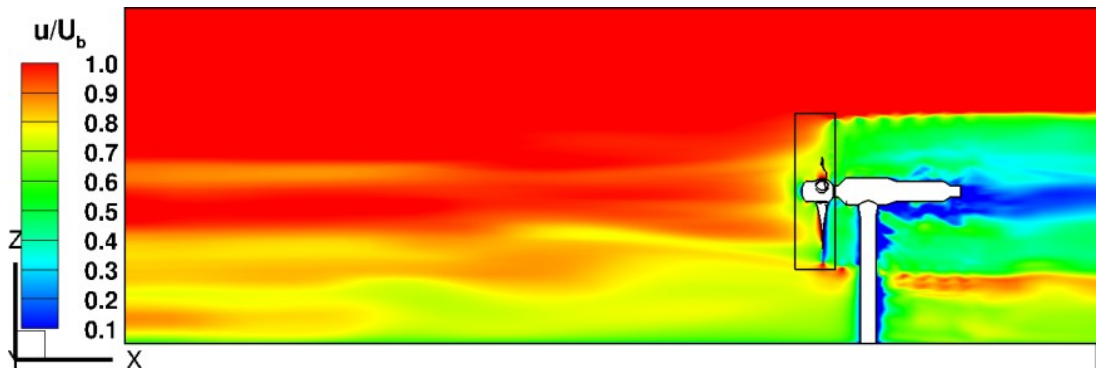

(d)

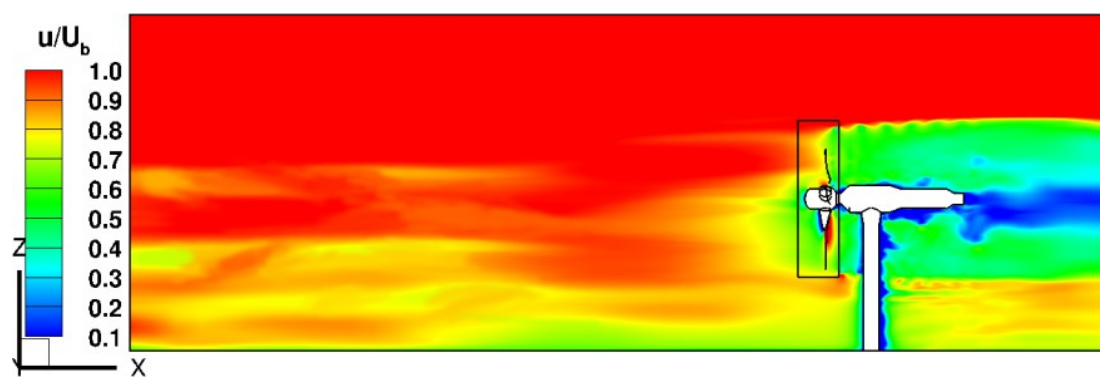

Figure 7. Velocity field; (a) RANS: no inlet turbulence (case A); (b) LES: no inlet turbulence (case B); (c) LES: synthetic turbulence based on channel flow (case C); (d) LES: synthetic turbulence with increased stresses and reduced length scales (case D).

Figure 8 shows vortex structure via isosurfaces of streamwise vorticity, coloured by 


$$
Q=\frac{1}{2}\left(S_{i j} S_{i j}-\Omega_{i j} \Omega_{i j}\right)
$$

With this definition (the sign is often reversed in the literature) negative $Q$ signifies an excess of rotational over shear strains. All cases show an interaction between vorticity emanating from the blade tips with that shed behind the tower. Onset turbulence causes distortion and aids in the break-up of the vortex structures. For both RANS and LES with low turbulence at inflow, tip-generated vortices are very persistent and start to break down primarily where they interact with the tower wake, whereas with onset turbulence they are distorted and diffused by the flow field. In case D, inflow stresses were increased and length scales decreased to match data at hub height; both effects accentuate the vortex breakdown.

(a)

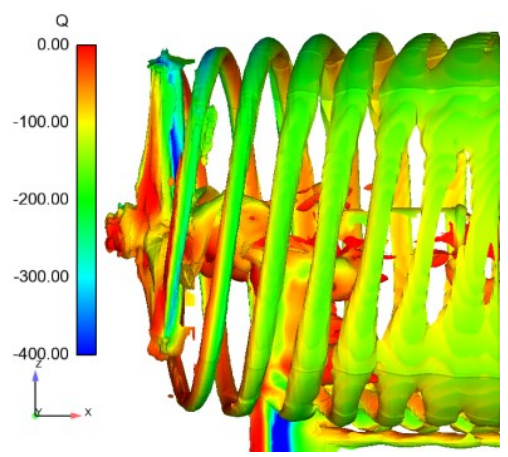

(c)

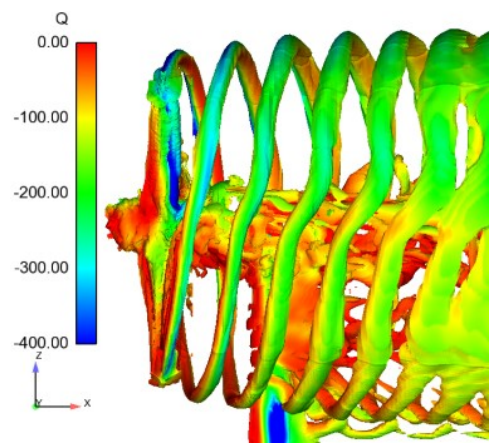

(b)

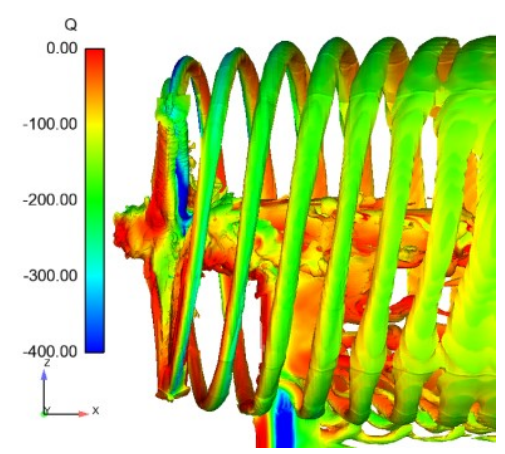

(d)

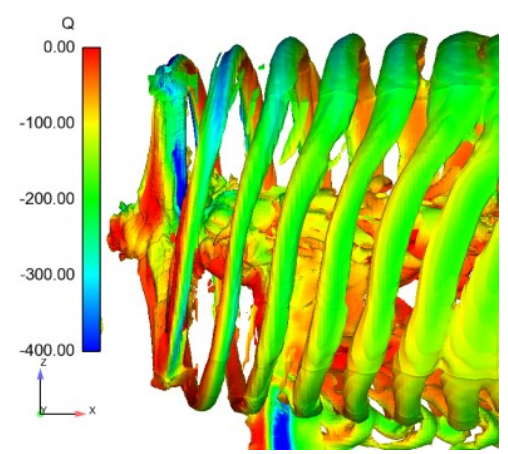

Figure 8. Instantaneous LES flow field showing vortical structures near the rotor: cases as in Figure 7.

Figure 9 shows development of the streamwise mean-velocity $(U)$ profile on the centreplane, from just downstream of the nacelle to $8 D$ downstream of the rotor, for low- and highturbulence LES simulations. In both cases the wake has two main features: a narrow, but expanding, central core associated with the nacelle blockage (with minor recirculation) and a broader wake approximating the rotor swept area, with slow spreading and velocity recovery. Over the majority of the swept area downstream the streamwise velocity is about half that in the approach flow. Wake recovery is slightly faster for the high-turbulence case, but the twopart wake structure, boundaries and velocity deficit are easily detectable at $8 D$ downstream of the rotor. With power output typically depending on the cube of flow speed this has implications for the layout of multiple turbines in an array, although successive rows may be staggered laterally to benefit from increased velocity in the bypass region outside the wake. 


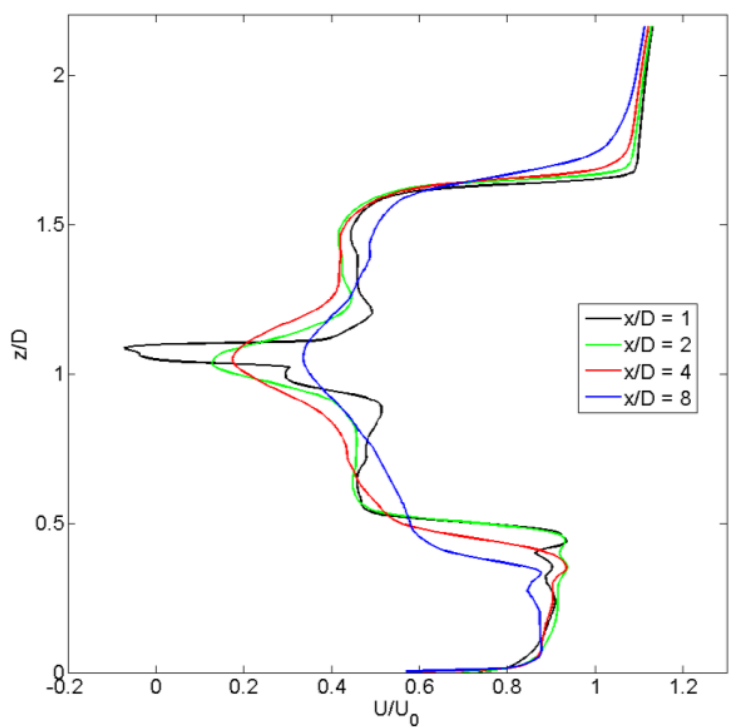

(a)

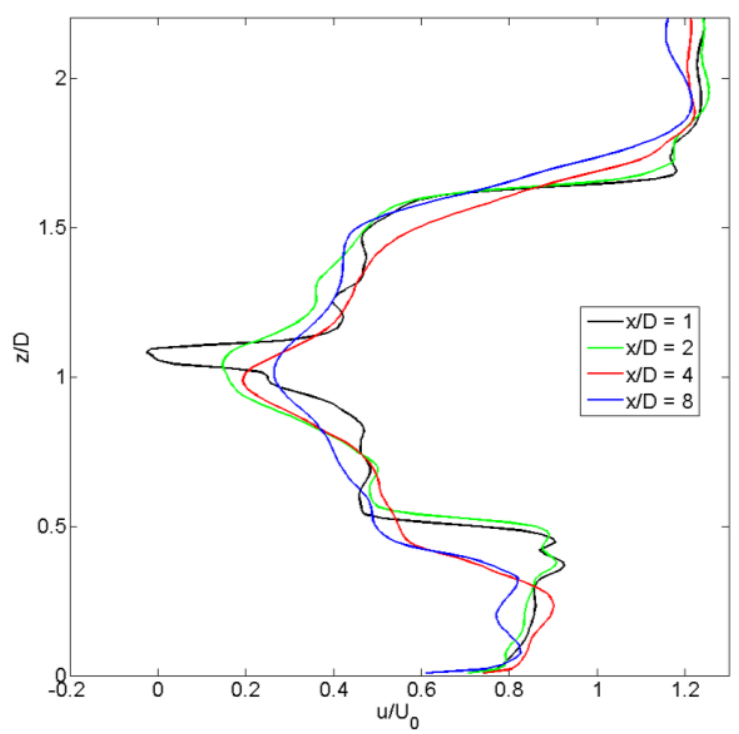

(b)

Figure 9. Downstream development of streamwise mean velocity: (a) no inlet turbulence (case B); (b) synthetic inflow turbulence (case D).

Figure 10 shows downstream development of the turbulent kinetic energy $(k)$ profile. Again there are two distinct wake features - local maxima corresponding to the shear layers originating on the surface of the nacelle, which diminish with distance, and those associated with the blade-tip vortices. In the low-onset-turbulence case, persistent blade-tip vorticity enhances mean-shear production of $k$ and its magnitude in this outer region actually increases with downstream distance, at least as far as the end of the computational domain. In the highonset-turbulence case, however, vortices are more quickly broken down and the level of enhanced turbulence downstream of the blade tips diminishes slightly with distance.

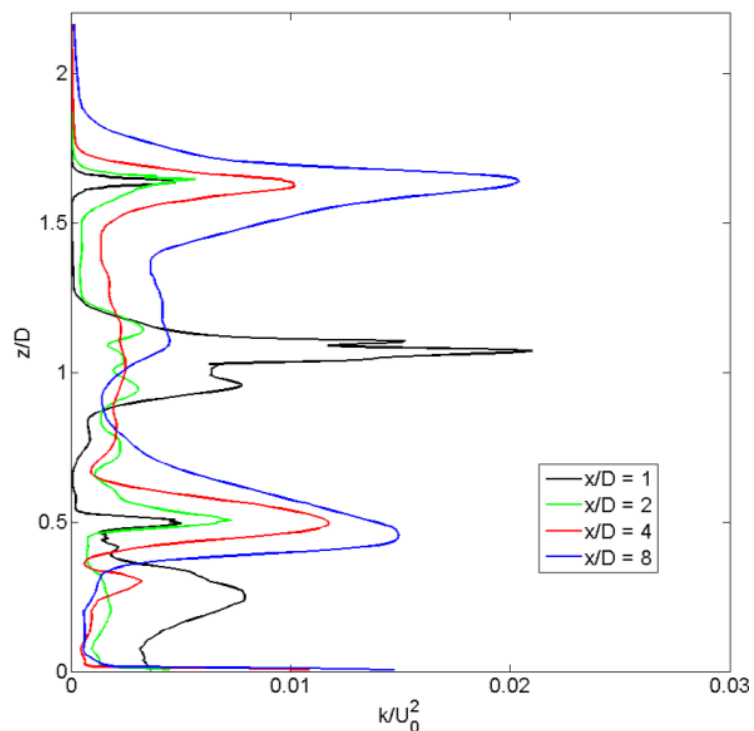

(a)

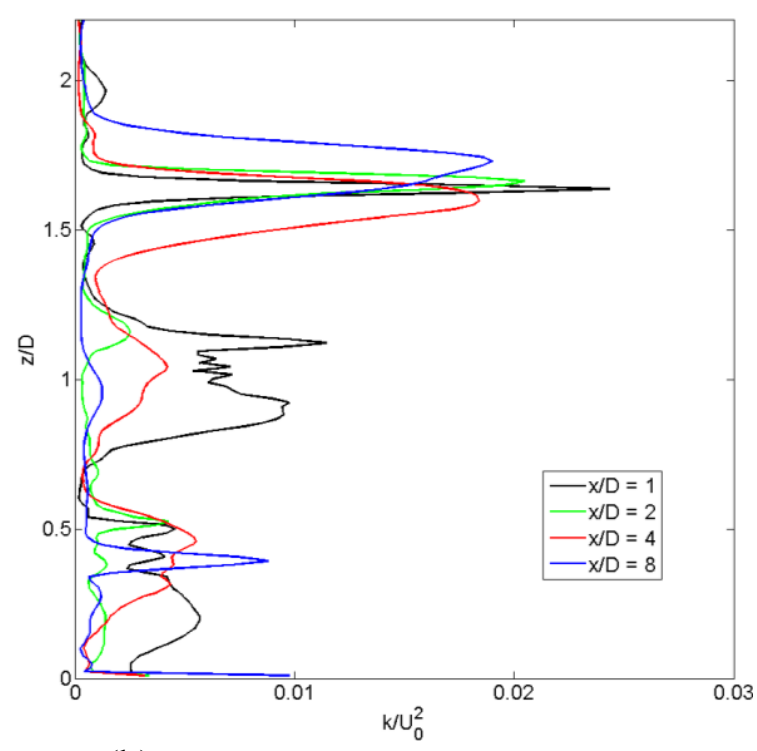

(b)

Figure 10. Downstream development of turbulent kinetic energy: (a) no inlet turbulence (case B); (b) synthetic inflow turbulence (case D). 
The cross-stream behaviour of instantaneous streamwise velocity $u$ and turbulent kinetic energy $k$ is shown in Figures 11 and 12 respectively for realistic inflow turbulence (case D). The velocity wake retains sharp edges, but with a boundary distorted by ambient turbulence. Turbulent kinetic energy is enhanced in the persistent maxima associated with tip vortices. Maxima from the shear layers on the nacelle and support tower are prominent at $1 D$ downstream, but decay significantly downstream. Note that $k$ is a time-averaged quantity, so asymmetry and small local peaks in the ambient flow are artefacts of a relatively short averaging time.

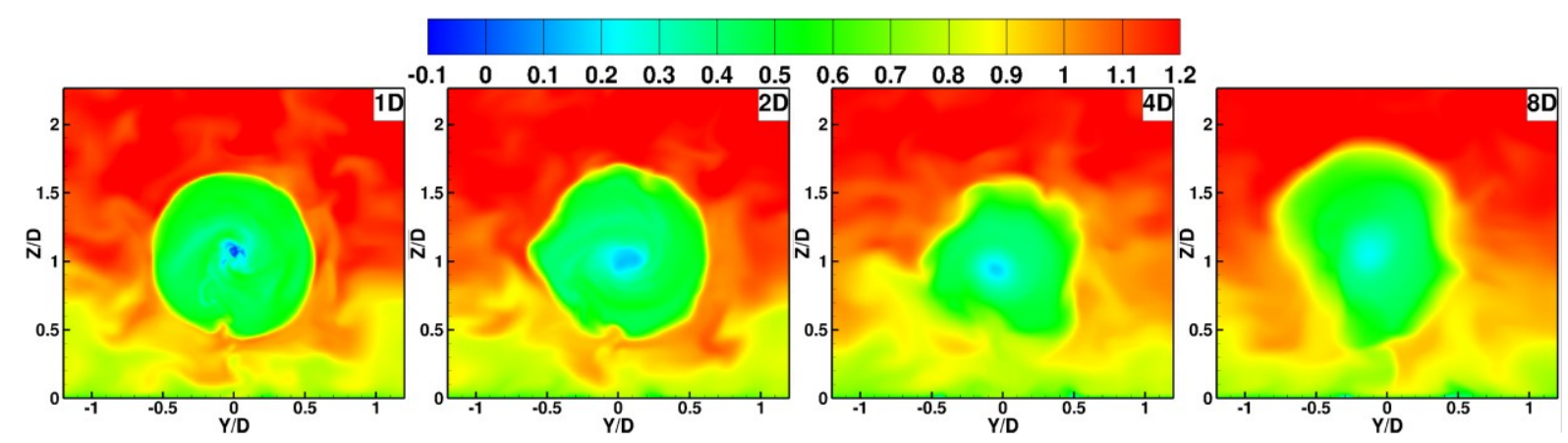

Figure 11. Cross-stream distribution of instantaneous streamwise velocity $\left(u / U_{0}\right)$ downstream of the rotor.
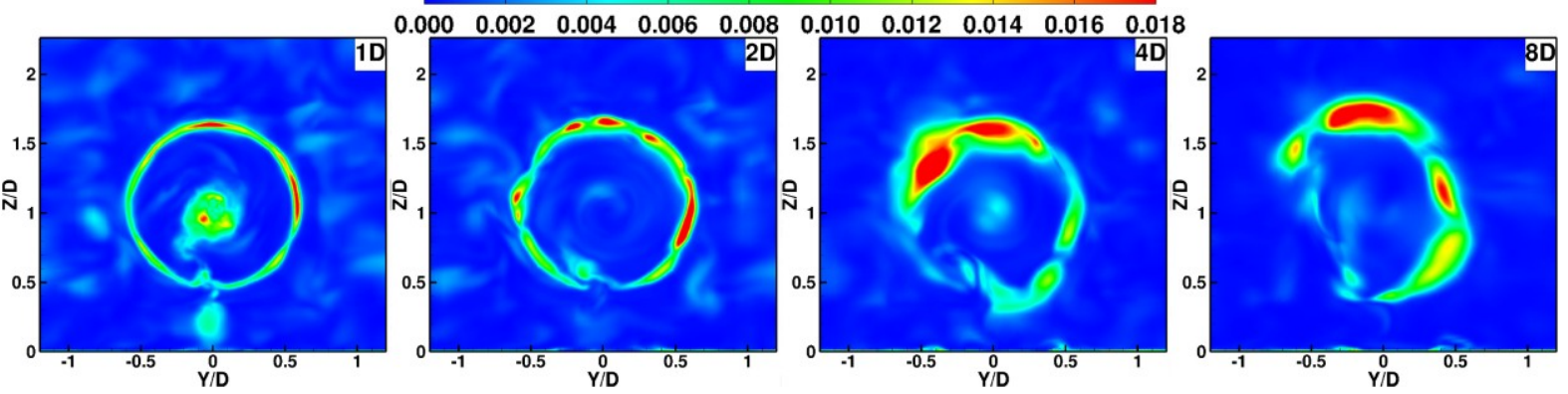

Figure 12. Cross-stream distribution of turbulent kinetic energy $\left(k / U_{0}^{2}\right)$ downstream of the rotor.

\subsection{Blade Pressure Distributions}

Differences between RANS and LES simulations in blade-generated turbulence are examined by plotting the pressure coefficient

$$
c_{P}=\frac{p-p_{r e f}}{\frac{1}{2} \rho U_{a z i}^{2}}
$$

on one blade at various radii. Here, pressure is normalised by local azimuthal speed $U_{a z i}=\Omega R$, rather than an approach-flow velocity, to reflect more accurately the onset flow to each blade, whilst negative pressures are plotted upward to emphasise lift. Figure 13a shows an instantaneous snapshot, whilst Figure 13b shows $c_{p}$ values based on average pressure over several cycles. In low-onset-turbulence (cases A and B), RANS and LES predict similar 
average pressures, but only LES can resolve the time-varying fluctuations associated with blade-generated turbulence that occur beyond about 50\% chord and 50\% tip radius. For case $\mathrm{D}$, onset turbulence augments instantaneous $c_{p}$ fluctuations and also increases slightly the difference in mean pressure between suction and pressure surfaces, which ultimately results in higher thrust and power coefficients (see below).

460

461

462

463

464

465

466

467

468

469

470

471

472

473

474

475

476

477 (a)
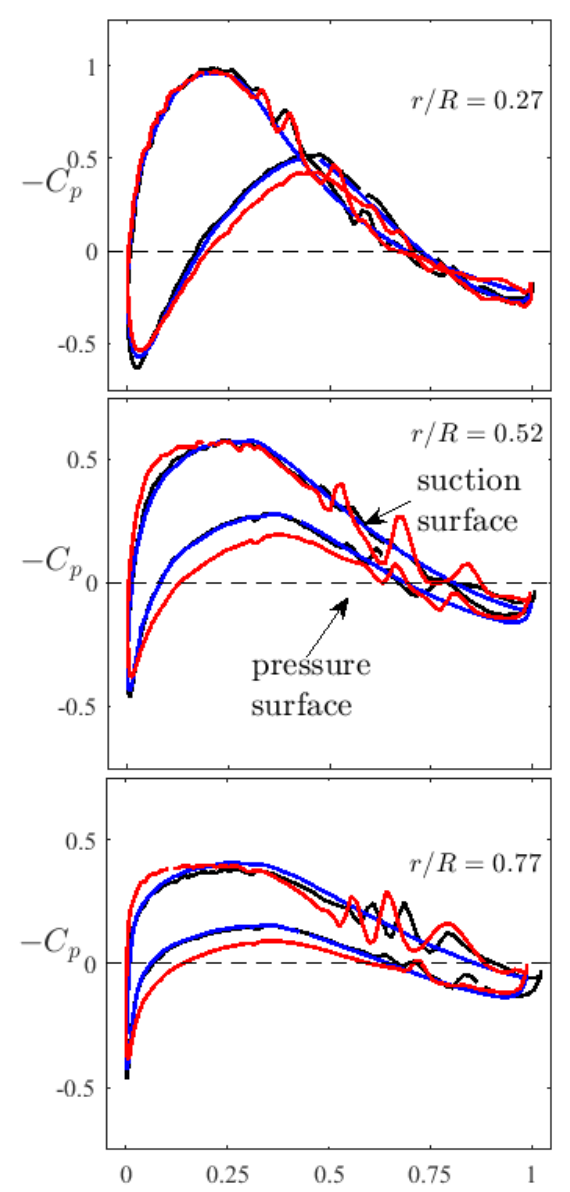

$x / C$

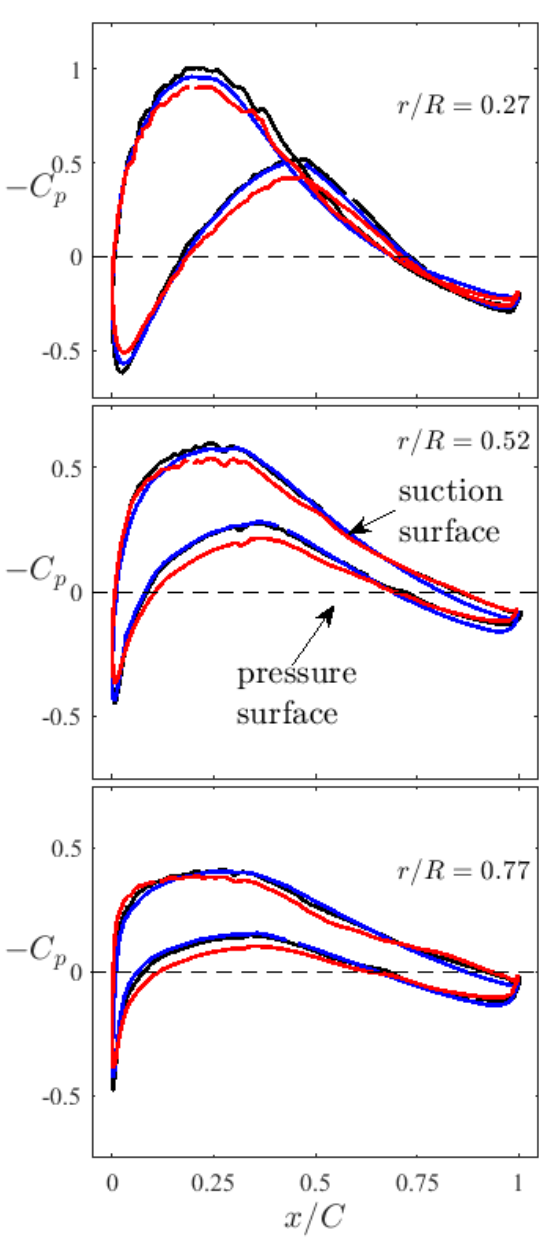

Figure 13. Pressure coefficient on blade surfaces for zero inflow turbulence - case A: RANS (blue), case B: LES (black) - and representative inflow turbulence - case D (red);

(a) instantaneous; (b) average.

\subsection{Thrust and Power Coefficients}

Figure 14 shows phase-averaged whole-rotor power and thrust coefficients, comparing data from the full-scale turbine with low-turbulence RANS and LES simulations (cases A and B), as well as LES simulations with channel-flow-derived inflow turbulence (cases $C$ and $D$ ). Experimental data indicates a power coefficient of about $0.43-0.44$ (sensitive to sampling interval on both power and velocity); this range is indicated by dashed lines in Figure 14b. No experimental data is available for thrust coefficient. Averaging started after one complete domain pass-through and was phase-averaged over the subsequent 21 rotations (Case A), 18 rotations (Case B) and 7 rotations (Cases $\mathrm{C}$ and $\mathrm{D}$ ). 


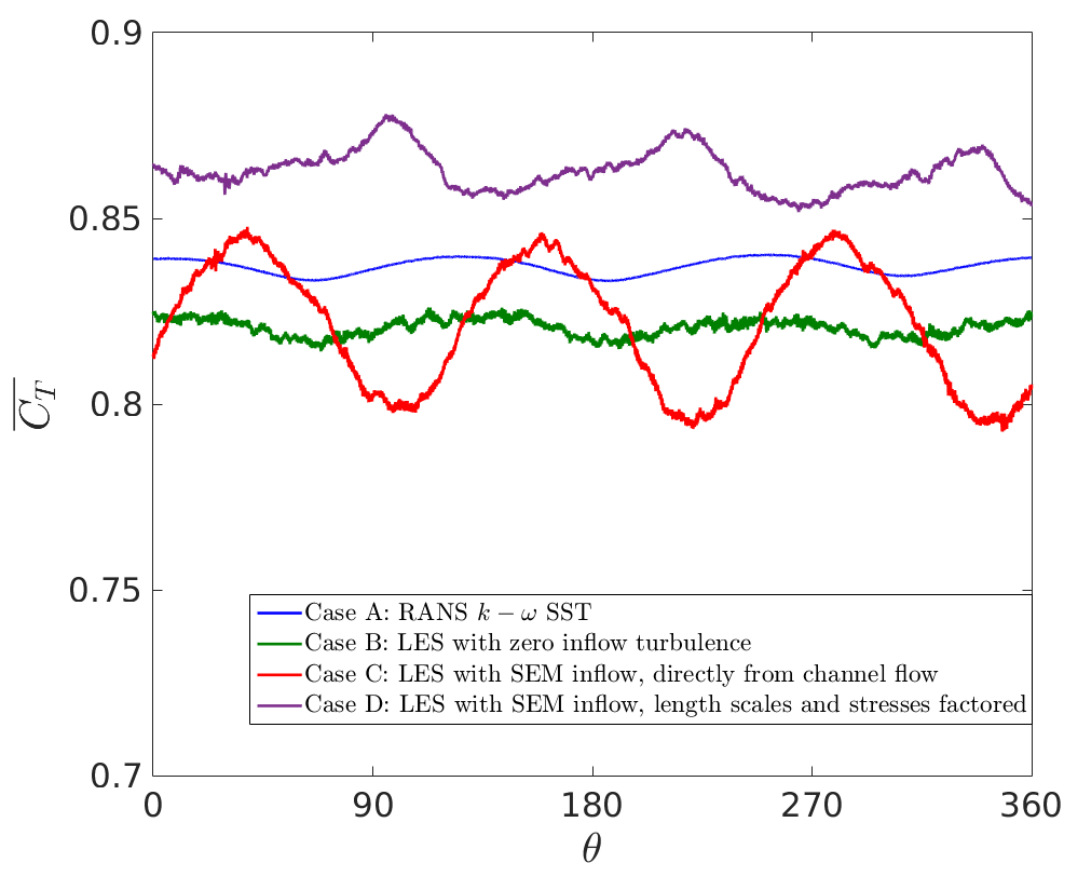

(a)

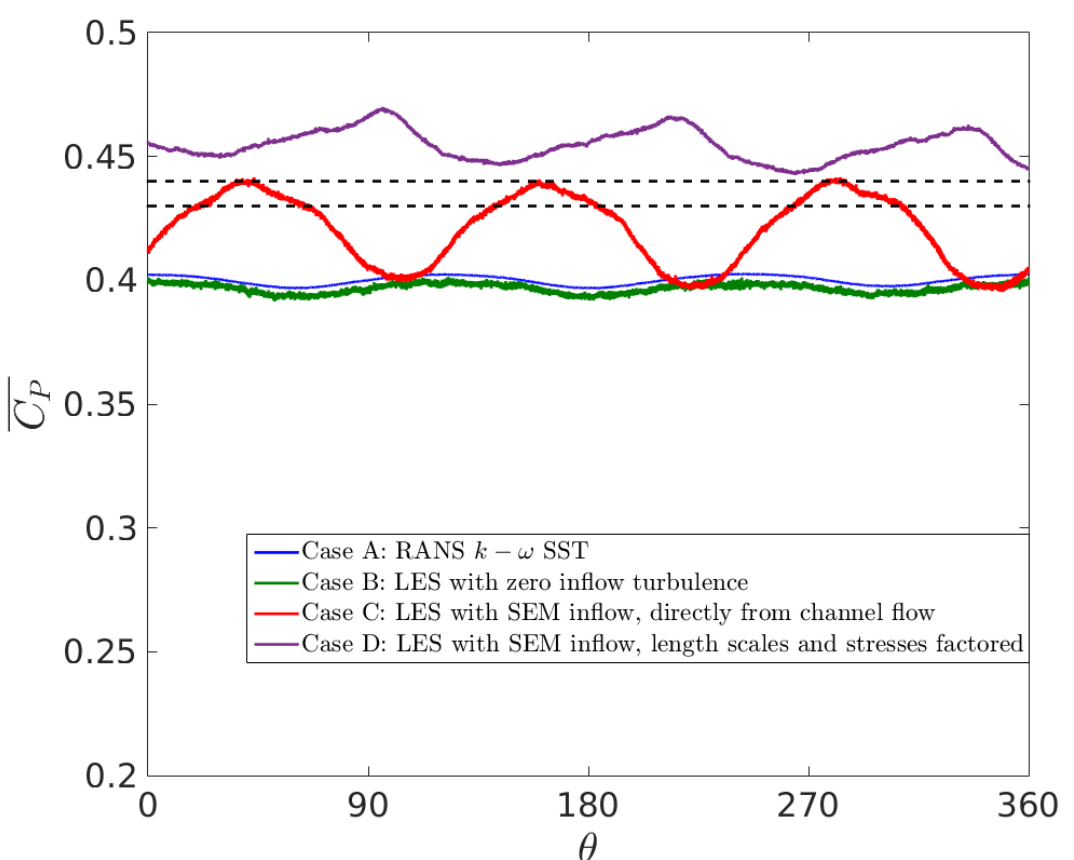

(b)

Figure 14. Phase-averaged load coefficients: (a) thrust coefficient; (b) power coefficient (experimental range shown dashed).

In the low-turbulence cases, cycle-average power coefficients from RANS and LES simulations (cases A and B) are very similar and both are slightly lower than the quoted experimental power coefficient. With more representative inflow turbulence (cases C and D) the average power coefficient is in better agreement with experiment. From power coefficient alone there is little to choose between the two turbulent-inflow cases, with one slightly underestimating power on average and the other slightly over-estimating it. Case D, with inflow stresses and lengthscales being factored to match experiment, is more consistent with the highly-site-specific turbulence and shows smaller fluctuations in phase-averaged load. 
494 Experiment data on $C_{P}$ fluctuations is not available to confirm whether this would be 495 observed in the field.

496

497

498

499

500

501

502

503

504

505

506

507

508

509

510

511

512

513

514

515

516

517

518

519

520

521

522

523

524

525

526

527

528

529

530

531

532

533
The phase variation in whole-rotor loads is at first sight challenging to explain - particularly the apparent difference in phase between the onset-turbulence cases $\mathrm{C}$ and $\mathrm{D}$. Rotation angle $\theta=0^{\circ}$ corresponds to one nominated blade being vertically upward. Any particular blade might be expected to receive the largest forcing when vertically upward and smallest forcing when vertically downward due to an (additive) combination of velocity shear and towerpassing effects. At first sight it might be anticipated that, summing over three blades, this would imply three maxima/minima in load coefficients for the whole rotor per cycle, with a maximum when one blade was vertically upward. Three maxima/minima per cycle are, indeed, evident, but the phases of the maxima cannot be inferred from the position of blades because individual blade forcing is a very complex function of angle. Indeed, if the fluctuation in loading on any particular blade were a simple sine function of rotation angle then, because

$$
\sin (\theta)+\sin (\theta+2 \pi / 3)+\sin (\theta+4 \pi / 3)=0
$$

for any angle $\theta$, the combined load fluctuation of all three blades would actually be zero. In other words, if there is an independent harmonic variation in forcing on all blades then the net contribution of all three blades to the rotor thrust or power coefficient would be flat. This clearly is not observed. We conclude that, although we can see the signature of three blades passing any reference point per turbine rotation, we cannot a priori determine at what angles the summed effect of three blades will exhibit a maximum, as this is a complex function of mean velocity shear, turbulence intensity and lengthscale, tower passing and possibly also upper and lower boundary constraints.

The variation in phase-averaged loading for the whole rotor with rotation angle is deceptively small compared with that for an individual blade on an individual cycle. Figure 15 shows the variation in instantaneous power coefficient for one blade during a single rotation (normalised by the cycle average). With low onset turbulence, RANS and LES show similar results, illustrating that excursions in power (or torque) on one blade due to the cyclical effect of velocity shear and tower passing are about $\pm 10 \%$ over a cycle, blade-generated turbulence (resolved by LES, but not by RANS) having only a modest effect when loads are integrated over the blade. By contrast, realistic inflow turbulence leads to variations in single-blade loading of more than a factor of 2 over timescales of less than half a turbine rotation, with significant implications for fatigue. Figure 15 also shows the expected behaviour when the turbulent lengthscales (and hence turbulent timescales) are reduced, with more rapid fluctuations in load. Note that in our simulations we have fixed the rotor speed. In reality, the response of the turbine will depend on the inertia of the rotor, the drive train and the control of blade pitch. 


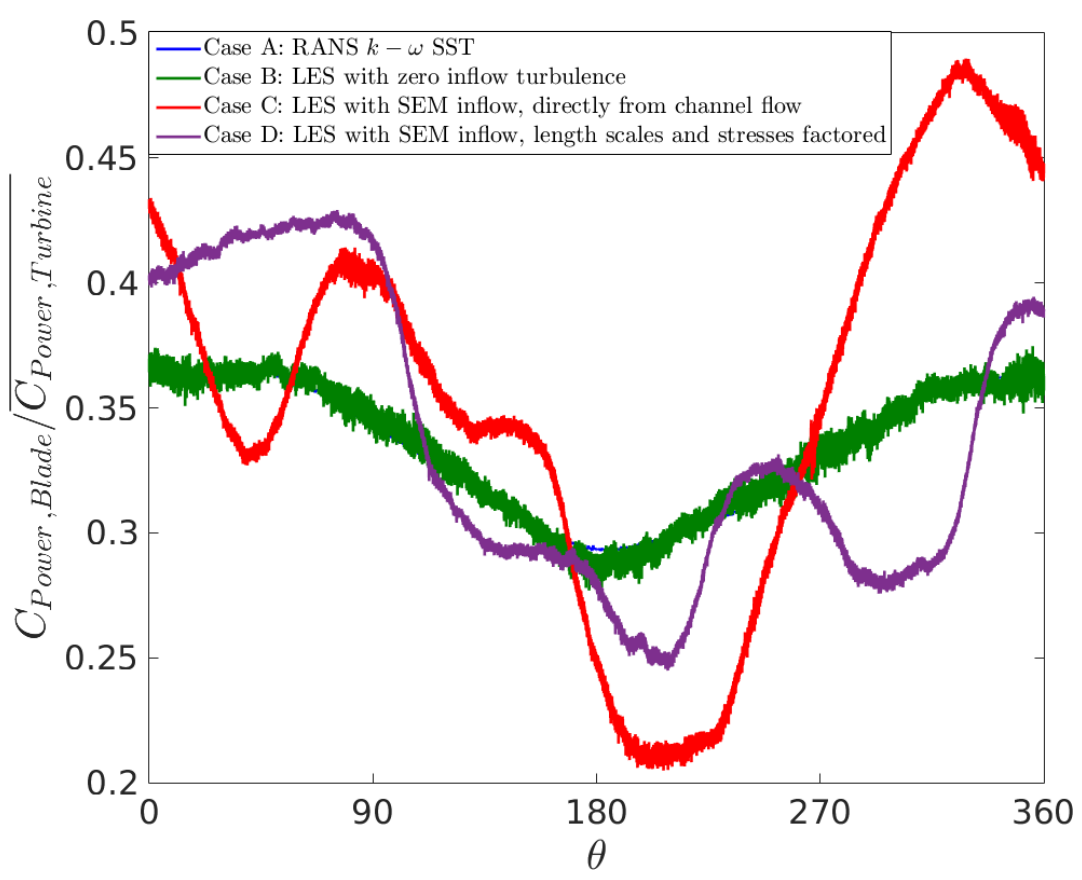

Figure 15. Power coefficient during one rotation (single blade, normalised by whole-rotor average).

\subsection{Blade Bending Moment}

Figure 16 shows experimental measurements of flapwise bending moment (at $r / R=0.272$, normalised by the cycle mean) for cycles from one 10-minute sample where the $30 \mathrm{~s}$ average of the reference velocity is in the range $1.75-1.85 \mathrm{~m} \mathrm{~s}^{-1}$. Considerable variation from one cycle to another is evident. Using the phase-averaged mean and the standard deviation from these cycles, Figure 17 presents this variation in an alternative form, and compares with the various LES simulations.

For a constant-speed rotor, fluctuations in load coefficients on a single blade have a number of sources:

- tower-passing and velocity-shear frequency $f_{0}=1 / T_{0}$, where $T_{0}$ is the period of a single rotation; (note that the whole rotor, with three blades, will exhibit key frequency $3 f_{0}$ );

- blade-generated turbulence;

- approach-flow turbulence.

For zero-inlet-turbulence LES (case B), Figure 17 shows that there is negligible variation in flapwise bending moment and therefore blade-generated turbulence is not the main source of fluctuations in bending moment. Approach-flow turbulence increases both phase-averaged fluctuations (solid lines) and between-cycle variation (shaded regions). With realistic inflow turbulence (case D), significant cycle-to-cycle variation in bending moments is evident, although, due to the small number of rotations that we have been able to simulate with LES, phase-averaged variation is not fully developed (hence the "wiggles") and the intra-cycle variation (width of the shaded region) is under-predicted. 


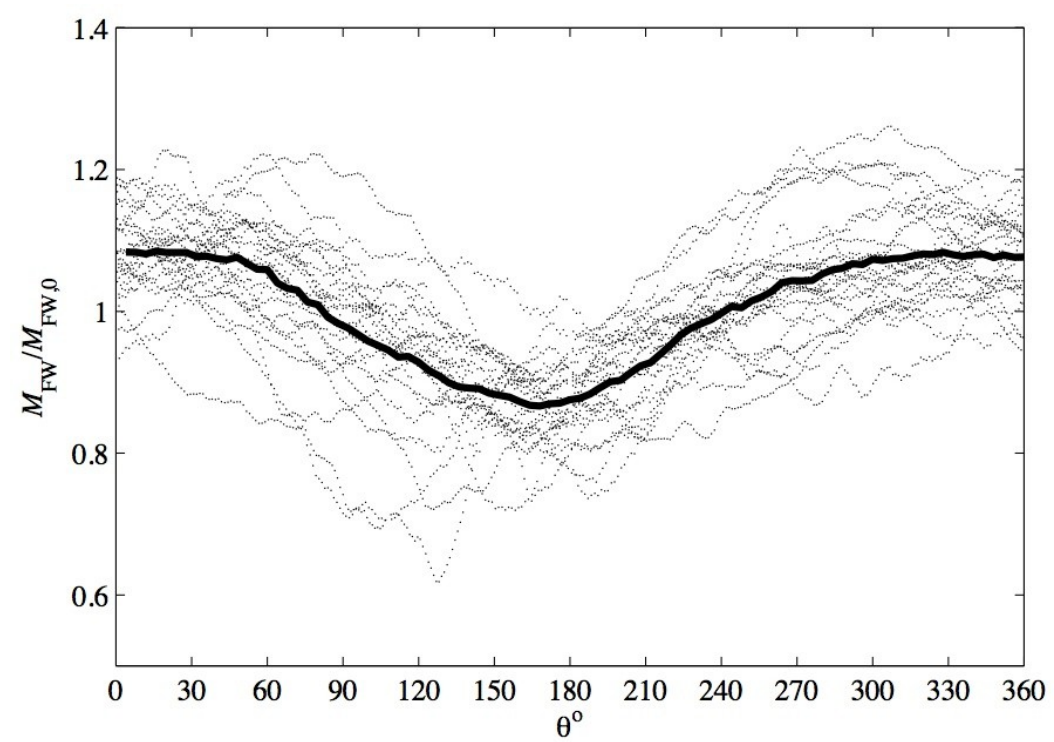

Figure 16. Variation of experimental flapwise bending moment (normalised by cycle mean) with blade position $(\theta)$ during a 10-minute sample for cycles where the $30 \mathrm{~s}$ average $U_{\text {ref }}$ is in the range 1.75 to $1.85 \mathrm{~m} \mathrm{~s}^{-1}$; phase average (solid) is also shown.

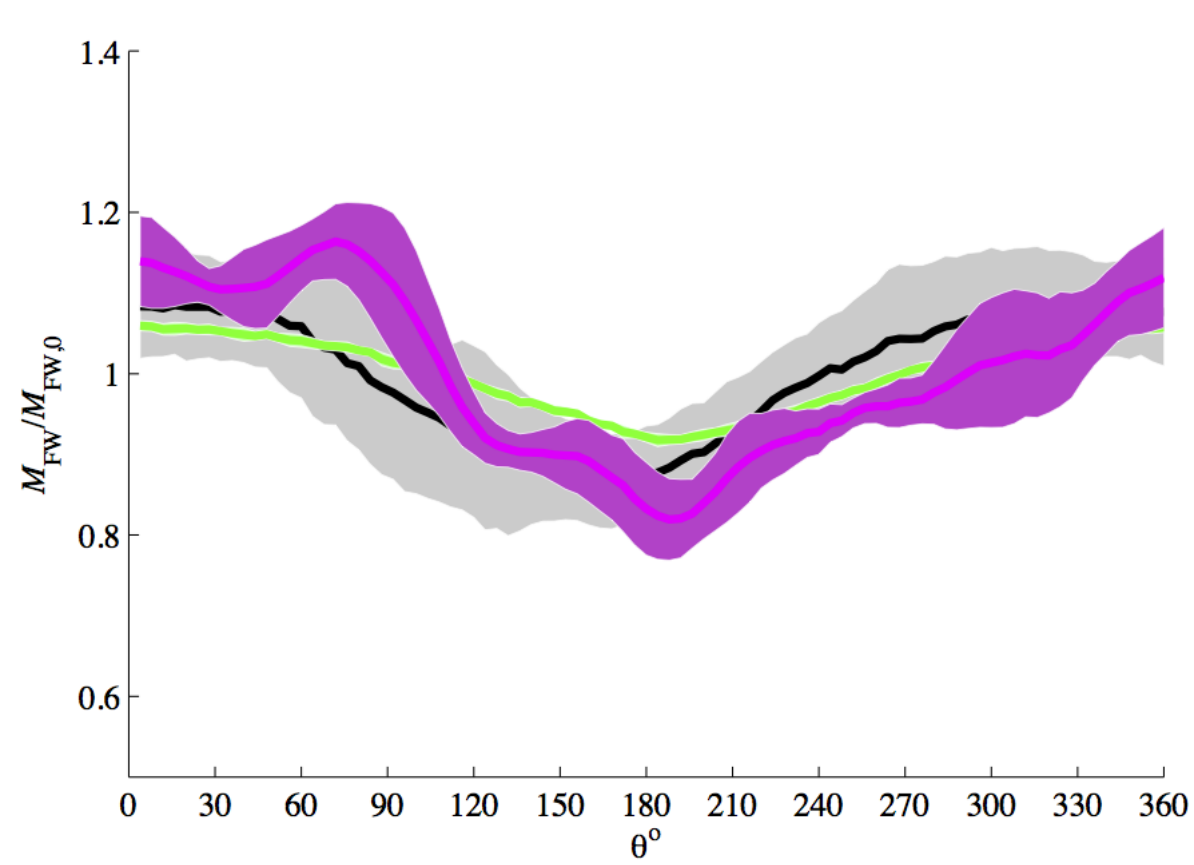

Figure 17. Variation of flapwise bending moment (normalised by cycle mean) for a single blade: experiment (black/grey); LES with no turbulence at inflow, Case B (green); LES with SEM inflow, Case D (purple); variation by one standard deviation either side is shaded.

The frequency distribution is also an important indicator of the relative importance of different sources of load fluctuation. Figure 18 shows the energy spectrum of the flapwise bending moment on a specific blade. Experimental data shown here was taken (at $50 \mathrm{~Hz}$ ) from one 10-minute sampling period where the average flow speed was $1.76 \mathrm{~m} \mathrm{~s}^{-1}$. To 
incorporate cases with different rotation speeds, spectral density is plotted against $f / f_{0}$, where $f_{0}$ is the primary tower-passing frequency. LES data is plotted for no inflow turbulence (case B) and for the higher-speed case with inflow turbulence (case D). Because of the fewer cycles available to sample in the CFD simulation, there is lower total variance; this has been overcome by normalising by the overall energy.

The distribution of spectral energy may be examined by considering the relative proportions at tower-passing frequency $\left(f / f_{0}=1\right)$, low- to mid-frequencies associated with onset turbulence, and the high frequencies typical of blade-generated turbulence $\left(f / f_{0}>20\right)$. Figure 18 shows that, with zero onset turbulence, the relative amount of energy is too low in the mid-frequency range. (Note that normalisation on total energy artificially amplifies the apparent spectral energy to the right of the graph.) The relative contribution of load fluctuations from the different frequency ranges is much more satisfactorily reproduced by case D with appropriately factored inflow turbulence. (Note that experimental measurements were taken at $50 \mathrm{~Hz}$, so the local spectral peak at $f / f_{0}=100$, which corresponds to a frequency of $20 \mathrm{~Hz}$, is unexplained, but may correspond to a natural frequency of the

603

604

605

606

607

608

609

610

611

612

613

614

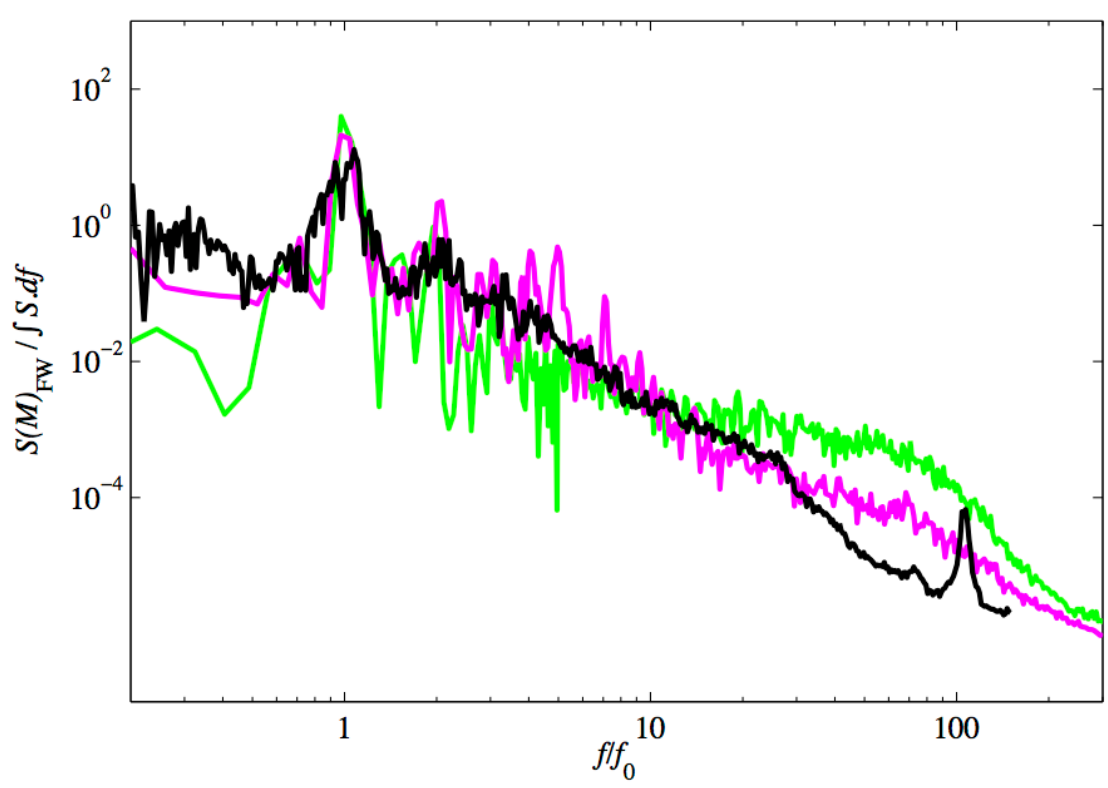

Figure 18. Spectrum of flapwise bending moment at $r / R=0.272$, normalised by total variance. Black - experiment; green - LES with no inflow turbulence (case B); purple - LES with turbulent inflow (case D).

Figure 19 shows a similarly-normalised energy spectrum of flapwise bending moment near blade root on a specific blade for RANS and LES closures. The former is not individualeddy-resolving, and lacks the energy in the higher frequencies associated with bladegenerated turbulence. 
615

616

617

618

619

620

621

622

623

624

625

626

627

628

629

630

631

632

633

634

635

636

637

638

639

640

641

642

643

644

645

646

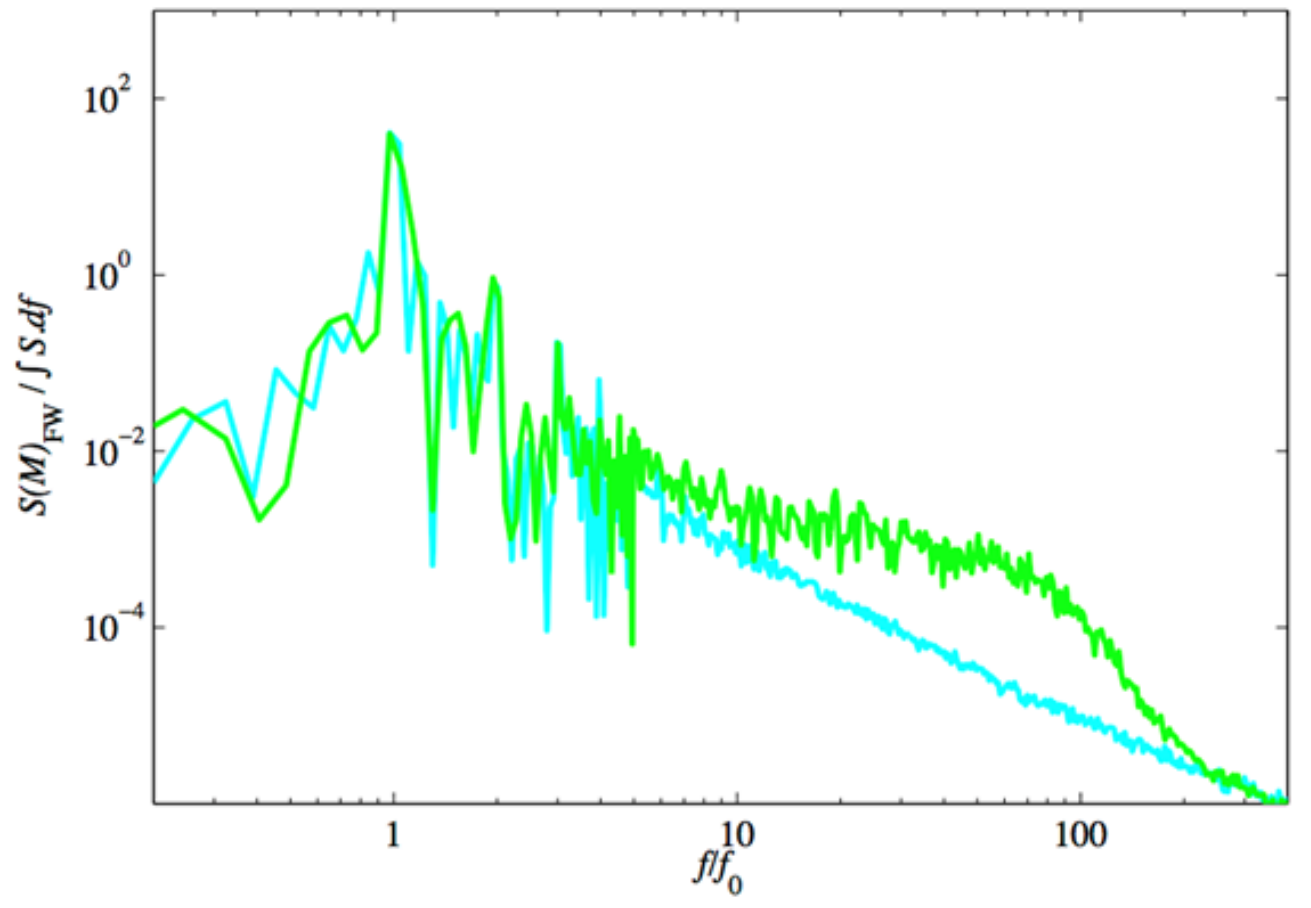

Figure 19. Spectrum of flapwise bending moment, comparing RANS (cyan) and LES (green) closures, both with no turbulence at inflow (cases A and B).

\section{CONCLUSIONS}

CFD simulations have been performed for a geometry-resolved tidal-stream turbine, of $18 \mathrm{~m}$ diameter and rated at $1 \mathrm{MW}$, for which fluctuating load data (power coefficient and bladebending moments) is available from measurements during power generation. Low-turbulence inflow has been simulated using both RANS (with the SST $k$ - $\omega$ model) and LES (with the Germano-Lilly dynamic subgrid model), whilst LES calculations with a synthetic-eddy model and profiles of Reynolds stresses derived from a separate channel-flow calculation have been conducted to simulate load fluctuations under onset turbulence characteristic of the flow measured at the deployment site.

The simulated velocity field indicates that the turbine rotor influences axial velocity and approach-flow turbulent structures to about $1 D$ upstream of the rotor, with velocity deficit and enhanced turbulence extending beyond the $10 \mathrm{D}$ downstream simulation extent. The twopart wake structure consists of a high-velocity-deficit, but rapidly-recovering, inner wake downstream of the nacelle and a slowly-spreading, broader wake in the rotor shadow, bounded by persistent blade-tip vortices.

For the low-turbulence case, RANS and LES predict similar phase-averaged loads and blade pressures. Thus, the less-computationally-demanding RANS approach would be sufficient to determine mean loads, at least near design operating conditions.

LES additionally resolves blade-generated turbulence. In realistic turbulent conditions, however, this contributes a small component of the overall load fluctuation, and only LES with representative synthetic turbulence at inflow is able to reproduce the full frequency range of bending-moment fluctuations that are experienced by individual blades whilst operating in a tidal stream. 
648 The work shows that LES is capable of realistic simulation of all fluctuating turbine loads for a single device, under a modest number of operating scenarios. Indeed, geometry-resolved CFD is also capable of revealing considerably more detail about the near-device flow field than can be captured in either field or laboratory experiments. The wake flow is, however under-resolved, so that simultaneous simulation of multiple machines in an array by this technique remains out of reach. One possible approach is to characterise enough of the nearwake structure of the flow to input this to a separate simulation for a downstream rotor.

655

Work is now under way to investigate load fluctuations on turbines with the additional source of variation due to waves. In addition, there is a continuing need for data and improved understanding of the characteristics of turbulence of tidal flows of this Reynolds number and of appropriate methods for simulating such onset flow.

660

661

662

663

\section{REFERENCES}

[1] Black and Veatch, Phase II UK Tidal Stream Energy Resource Assessment, Rep. 107799/D/2200/03 for Carbon Trust (2005).

[2] M. Lewis, S.P. Neill, P.E. Robins and M.R. Hashemi, Resource assessment for future generations of tidal-stream energy arrays, Energy, 83 (2015), 407-415.

[3] A.S. Bahaj, A.F. Molland, J.R. Chaplin and W.M.J. Batten, Power and thrust measurements of marine current turbines under various hydrodynamic flow conditions in a cavitation tunnel and a towing tank, Renewable Energy, 32 (2007) 407-426.

[4] N. Barltrop, K.S. Varyani, A. Grant, D. Clelland, and X.P. Pham, Investigation into wavecurrent interactions in marine current turbines, Proc. I. Mech. E. Part A: J. Power and Energy, 221 (2007) 233-242.

[5] E. Fernandez-Rodriguez, T. Stallard and P.K. Stansby, Experimental study of extreme thrust on a tidal stream rotor due to turbulent flow and with opposing waves, J. Fluids and Structures, 51 (2014) 354-361.

[6] T. Stallard, R. Collings, T. Feng and J. Whelan, Interactions between tidal turbine wakes: experimental study of a group of three-bladed rotors, Phil. Trans. Roy. Soc. A: Mathematical, Physical and Engineering Sciences, 371 (2013) 20120159. 
[7] L.E. Myers and A.S. Bahaj, Experimental analysis of the flow field around horizontal axis tidal turbines by use of scale mesh disk rotor simulators. Ocean Engineering, 37 (2010) $218-$ 227.

[8] A.S. Bahaj, W.M.J. Batten and G. McCann, Experimental verifications of numerical predictions for the hydrodynamic performance of horizontal axis marine current turbines, Renewable Energy, 32 (2007) 2479-2490.

[9] R. McSherry, J. Grimwade, I. Jones, S. Mathias, A. Wells and A. Mateus, 3D CFD modelling of tidal turbine performance with validation against laboratory experiments. 9th European Wave and Tidal Energy Conference, University of Southampton, England (2011).

[10] A. Mason-Jones, D.M. O'Doherty, C.E. Morris and T. O'Doherty, Influence of a velocity profile and support structure on tidal stream turbine performance, Renewable Energy, 52 (2013) 23-30.

[11] I. Afgan, J. McNaughton, D.D. Apsley, S. Rolfo, T. Stallard and P.K. Stansby, Turbulent flow and loading on a tidal stream turbine by LES and RANS, Int. J. Heat and Fluid Flow, 43 (2013) 96-108.

[12] J.N. Sørensen and W.Z. Shen, Numerical modelling of wind turbine wakes, J. Fluids Eng., 124 (2002) 393-399.

[13] H. Sarlak, T. Nishino, L.A. Martìnez-Tossas, C. Meneveau and J.N. Sørensen, Assessment of blockage effects on the wake characteristics and power of wind turbines, Renewable Energy, 93 (2016) 340-352.

[14] F. Porté-Agel, Y.-T. Wu, H. Lu and R.J. Conzemius, Large-eddy simulation of atmospheric boundary layer flow through wind turbines and wind farms, J. Wind Eng. Ind. Aerodyn., 99 (2011) 154-168.

[15] M.J. Churchfield, Y. Li and P.J. Moriarty, A large-eddy simulation study of wake propagation and power production in an array of tidal-current turbines, Phil. Trans. Roy. Soc. A: Mathematical, Physical and Engineering Sciences, 371 (2013) 20120421.

[16] A. Olczak, T. Stallard, T Feng and P.K.Stansby, Comparison of a RANS blade element model for tidal turbine arrays with laboratory scale measurements of wake velocity and rotor thrust, J. Fluids and Structures, 64 (2016) 87-106.

[17] D.D. Apsley, T. Stallard and P.K. Stansby, Actuator-line CFD modelling of tidal-stream turbines, 2nd Int. Conf. on Marine Renewable Energy (CORE2016), Glasgow (2016).

[18] D.R.J. Sutherland, B.G. Sellar, S. Harding and I. Bryden, Initial flow characterisation utilising turbine and seabed-installed acoustic sensor arrays, 10th European Wave and Tidal Energy Conference, Aalborg, Denmark (2013).

[19] J. McNaughton, S. Harper, R. Sinclair and B. Sellar, Measuring and modelling the power curve of a commercial-scale tidal turbine, 11th European Wave and Tidal Energy Conference, Nantes, France (2015). 
[20] S. Parkinson and W. Collier, Model validation of hydrodynamic loads and performance of a full-scale tidal turbine using Tidal Bladed, Int. J. Marine Energy, 16 (2016) 279-297.

[21] J. McNaughton, I. Afgan, D.D. Apsley, S. Rolfo, T. Stallard and P.K. Stansby, A simple sliding-mesh interface procedure and its application to the CFD simulation of a tidal-stream turbine, Int. J. Numer. Meth. Fluids, 74 (2014) 250-269.

[22] F.R. Menter, Two-equation eddy-viscosity turbulence models for engineering applications, AIAA J., 32 (1994) 1598-1605.

[23] M. Germano, U. Piomelli, P. Moin and W.H. Cabot, A dynamic subgrid-scale eddyviscosity model, Physics of Fluids A: Fluid Dynamics, 3 (1991) 1760 - 1765.

[24] D.K. Lilly, A proposed modification of the Germano subgrid-scale closure method, Physics of Fluids A: Fluid Dynamics, 4 (1992) 633 - 635.

[25] J. Smagorinsky, General circulation experiments with the primitive equations, (i) the basic experiment, Monthly Weather Review, 91 (1963) 99-164.

[26] N. Jarrin, R. Prosser, J. Uribe, S. Benhamadouche and D. Laurence, Reconstruction of turbulent fluctuations for hybrid RANS/LES simulations using a synthetic-eddy method, Int. 769 J. Heat and Fluid Flow 30 (2009) 435 - 442. 


\section{List of Figures}

Figure 1. Definition of axes for blade bending moments.

Figure 2. Computational domain and turbine position.

Figure 3. Computational mesh: (a) surface detail; (b) cross-stream mesh in the rotating region.

Figure 4. Velocity profiles at inlet: (a) representative flood-tide profile and channel-flow simulation; (b) comparison of channel-flow-derived streamwise mean and fluctuating velocities

Figure 5. Turbulence profiles from the channel-flow simulation: (a) Reynolds stresses; (b) length scales.

Figure 6. Eddy box for synthetic inflow turbulence.

Figure 7. Velocity field; (a) RANS: no inlet turbulence (case A); (b) LES: no inlet turbulence (case B); (c) LES: synthetic turbulence based on channel flow (case C); (d) LES: synthetic turbulence with increased stresses and reduced length scales (case D).

Figure 8. Instantaneous LES flow field showing vortical structures near the rotor: cases as in Figure 7.

Figure 9. Downstream development of streamwise mean velocity: (a) no inlet turbulence (case B); (b) synthetic inflow turbulence (case D).

Figure 10. Downstream development of turbulent kinetic energy: (a) no inlet turbulence (case B); (b) synthetic inflow turbulence (case D).

Figure 11. Cross-stream distribution of instantaneous streamwise velocity $(u / U 0)$ downstream of the rotor.

Figure 12. Cross-stream distribution of turbulent kinetic energy $(k / U 02)$ downstream of the rotor.

Figure 13. Pressure coefficient on blade surfaces for zero inflow turbulence - case A: RANS (blue), case B: LES (black) - and representative inflow turbulence - case D (red); (a) instantaneous; (b) average.

Figure 14. Phase-averaged load coefficients: (a) thrust coefficient; (b) power coefficient (experimental range shown dashed).

Figure 15. Power coefficient during one rotation (single blade, normalised by whole-rotor average).

Figure 16. Variation of experimental flapwise bending moment (normalised by cycle mean) with blade position $(\theta)$ during a 10 -minute sample for cycles where the $30 \mathrm{~s}$ average Uref is in the range 1.75 to $1.85 \mathrm{~m} \mathrm{~s}^{-1}$; phase average (solid) is also shown. 
822 Figure 17. Variation of flapwise bending moment (normalised by cycle mean) for a single 823 blade: experiment (black/grey); LES with no turbulence at inflow, Case B (green); LES with SEM inflow, Case D (purple); variation by one standard deviation either side is shaded.

Figure 18. Spectrum of flapwise bending moment at $r / R=0.272$, normalised by total variance. Black - experiment; green - LES with no inflow turbulence (case B); purple - LES with turbulent inflow (case D).

831

Figure 19. Spectrum of flapwise bending moment, comparing RANS (cyan) and LES (green)

832 closures, both with no turbulence at inflow (cases A and B).

\section{List of Tables}

836

837

Table 1. Summary of flow cases considered. 